ORIGINAL ARTICLE

\title{
Air pollution and inflammation in type 2 diabetes: a mechanism for susceptibility
}

\author{
M S O'Neill, A Veves, J A Sarnat, A Zanobetti, D R Gold, P A Economides, E S Horton, J Schwartz
}

Occup Environ Med 2007;64:373-379. doi: 10.1136/oem.2006.030023

See end of article for authors' affiliations

\section{Correspondence to:} DrM S O'Neill, University of Michigan School of Public Health, 6631 SPH Tower 109 South Observatory, Ann Arbor, MI 48109, USA; marieo@umich.edu

Accepted 1 December 2006 Published Online First 19 December 2006
Background: Particulate air pollution has been associated with several adverse cardiovascular health outcomes, and people with diabetes may be especially vulnerable. One potential pathway is inflammation and endothelial dysfunction-processes in which cell adhesion molecules and inflammatory markers play important roles.

Aim: To examine whether plasma levels of soluble intercellular adhesion molecule 1 (ICAM-1), vascular cell adhesion molecule 1 (VCAM-1) and von Willebrand factor (VWF) were associated with particle exposure in 92 Boston area residents with type 2 diabetes.

Methods: Daily average ambient levels of air pollution (fine particles ( $P M_{2.5}$ ), black carbon (BC) and sulphates) were measured approximately $500 \mathrm{~m}$ from the patient examination site and evaluated for associations with ICAM-1, VCAM-1 and VWF. Linear regressions were fit to plasma levels of ICAM-1, VCAM- 1 and VWF, with the particulate pollutant index, apparent temperature, season, age, race, sex, glycosylated haemoglobin, cholesterol, smoking history and body mass index as predictors.

Results: Air pollutant exposure measures showed consistently positive point estimates of association with the inflammatory markers. Among participants not taking statins and those with a history of smoking, associations between $\mathrm{PM}_{2.5}, \mathrm{BC}$ and VCAM-1 were particularly strong.

Conclusions: These results corroborate evidence suggesting that inflammatory mechanisms may explain the increased risk of air pollution-associated cardiovascular events among those with diabetes.
O utdoor air quality standards worldwide are intended to protect the most sensitive people in the population, yet studies linking outdoor pollution and health have observed associations even at pollutant levels well below the standards. ${ }^{2}$ One important regulated pollutant is particles $<2.5 \mu \mathrm{m}$ in aerodynamic diameter $\left(\mathrm{PM}_{2.5}\right)$, formed as a result of fossil-fuel combustion by motor vehicles and stationary sources such as power plants. These fine particles are of concern for health as they can deposit in the lower airways and gasexchanging portions of the lung, even reaching the circulatory system. ${ }^{3}$ Exposure to increased levels of outdoor particulate air pollution has been consistently linked to cardiovascular morbidity and mortality, and to changes in subclinical indicators of cardiovascular function. ${ }^{4}$ Inflammation due to oxidative stress may be one responsible mechanism, ${ }^{4}$ as suggested by both animal and human studies. ${ }^{5-7}$

Individuals with diabetes are at greater risk of dying ${ }^{8}$ and being hospitalised for heart disease $\mathrm{e}^{9}$ during periods of high air pollution. Long-term exposure to $\mathrm{PM}_{2.5}$ was associated with a higher relative risk of mortality among people with diabetes compared with the general population. ${ }^{10}$ Hence, those with diabetes may be considered a sensitive population. Examining the potential biological mechanisms responsible for this enhanced susceptibility, and identifying specific air pollution sources that may be more toxic, is therefore a priority for researchers and policy makers. ${ }^{4}$ Obesity is prevalent among people with diabetes and involves an increased inflammatory burden, thus lending plausibility to the idea that inflammation is involved in sensitivity to the cardiovascular effects of particles. ${ }^{11}{ }^{12}$

Inflammation is a key pathway leading to atherosclerosis and subsequent adverse cardiovascular events, ${ }^{13}$ and several blood markers of inflammation are being evaluated for their ability to predict prevalent or incident cardiovascular disease. These include the intercellular adhesion molecule 1 (ICAM-1) and the vascular cell adhesion molecule 1 (VCAM-1), which are expressed on cell surfaces and are also found, in soluble form, in the plasma. $^{14}$ Another inflammatory marker is von Willebrand factor (vWF): a polypeptide involved in the thrombotic pathway, and a marker of endothelial damage or dysfunction. ${ }^{15}$ Increased plasma levels of soluble ICAM-1 and VCAM-1, and VWF have been associated with inflammatory, cardiovascular and neoplastic disease outcomes, ${ }^{14-21}$ although VCAM-1 associations have been less consistent than for ICAM$1 .{ }^{17} 1822$ Prospective studies have linked vWF with risk of heart attack and coronary heart disease. ${ }^{16}{ }^{23}$ Increased levels of vWF and soluble VCAM-1 and ICAM-1 are also associated with diabetes prevalence, ${ }^{24} 25$ and higher VCAM- 1 and ICAM-1 levels are associated with development of type 2 diabetes and its complications. ${ }^{25} 26$

A few toxicological and epidemiological studies have examined the associations between ICAM-1, VCAM-1, and/or vWF levels and particle exposures, ${ }^{27-33}$ but none focused specifically on individuals with diabetes. Previously, we evaluated impaired vascular reactivity as one potential mechanism for increased sensitivity to particle-mediated health effects. ${ }^{34}$ This study examines whether ambient levels of airborne particles are associated with inflammation, as marked by increased ICAM-1, VCAM-1 and VWF plasma levels, among people with diabetes residing in metropolitan Boston, Massachusetts, USA.

Abbreviations: AT, apparent temperature; $\mathrm{BC}$, black carbon; BMl, body mass index; HbAlc, glycosylated haemoglobin; ICAM-1, intercellular adhesion molecule 1; $\mathrm{PM}_{2.5}$, particles $<2.5 \mu \mathrm{m}$ in aerodynamic diameter, known as fine particles; $\mathrm{PM}_{10}$, particles $<10 \mu \mathrm{m}$ in aerodynamic diameter; $\mathrm{SO}_{4}{ }^{2-}$, sulphate; VCAM-1, vascular cell adhesion molecule $1 ; \mathrm{vWF}$, von Willebrand factor 


\section{METHODS}

\section{Study participants}

In this cross-sectional study, participants were enrolled in four clinical trials conducted at the Joslin Diabetes Center and Beth Israel Deaconess Medical Center, Boston, Massachusetts, USA, to examine the effects of drugs $s^{35-37}$ and vitamin E supplementation on various indicators of cardiovascular health. ${ }^{38}$ Data taken at baseline examinations (before randomisation to treatment) between May 1998 and December 2002 were pooled for this analysis. Study participants analysed for the present study had type 2 diabetes as defined by American Diabetes Association criteria. ${ }^{38}$ Although people without diagnosed diabetes were included in some of the trials, sample sizes were small, limiting the ability to make useful comparisons, ${ }^{34}$ and the current goal was to evaluate potential mechanisms only among the group already identified as being susceptible in previous populationbased studies.

\section{Ethical approval}

The original protocols and data used for the present analysis were approved by the ethics committee or institutional review board at participating institutions, and procedures followed institutional guidelines. All participants were recruited through local advertisement and gave written informed consent for the original trial protocol.

\section{Selection and exclusion criteria}

Participant exclusion criteria were developed for the clinical trials. We excluded subjects with overt diabetic complications, including severe peripheral somatic neuropathy by screening examination or macroalbuminuria (albumin/creatinine ratio $>300 \mathrm{mg} / \mathrm{g}$ ); those who had smoked in the past 6 weeks and those with congestive heart failure; atrial fibrillation; atrial flutter; ventricular tachycardia or fibrillation; stroke or transient ischaemic attack; uncontrolled hypertension (systolic blood pressure $>180 \mathrm{~mm} \mathrm{Hg}$ or diastolic blood pressure $>105 \mathrm{~mm} \mathrm{Hg}$ ); severe dyslipidaemia (triglyceride level $>600 \mathrm{mg} / \mathrm{dl}$ or cholesterol level $>350 \mathrm{mg} / \mathrm{dl}$ ); bypass surgery owing to peripheral vascular disease; seizure disorder; and those taking non-steroidal anti-inflammatory drugs or aspirin. Finally, subjects included in the current analysis were either not taking antihypertensive or lipid-lowering drugs, or were taking a stable dose of these medications for at least 6 months, with documented blood pressure and lipid control.

\section{Clinical measurements}

Clinical evaluations were made during the morning hours at the Joslin Diabetes Center's Clinical Research Center after an overnight fast. Weight, height and body mass index (BMI) were obtained using standard procedures, and a questionnaire on vital statistics, medical history and drug use was administered. A physician performed the general physical examination on all participants. Volunteers were asked not to take diabetes drugs (sulphonylureas or metformin) for the previous $12 \mathrm{~h}$, and those taking insulin were requested to abstain from taking rapidacting insulin on the morning of their evaluation. Blood was drawn from an antecubital vein, without venous stasis. Soluble ICAM-1, soluble VCAM-1 and VWF were measured in plasma in duplicate using the enzyme-linked immunosorbent assay method (R\&D Systems, Minneapolis, Minnesota, USA (soluble ICAM-1 and soluble VCAM-1); Asserachrom, American Bioproducts, Parsipanny, New Jersey, USA (vWF)) as has been reported in previous studies. ${ }^{25}$ Glycosylated haemoglobin (HbAlc) concentrations (an indicator of glycaemic load) in whole blood were determined using ion-exchange highperformance liquid chromatography.

\section{Air pollution and meteorology}

Air pollution concentrations were measured at a Harvard School of Public Health ambient monitoring site located approximately $1 \frac{1}{2} \mathrm{~km}$ from the clinic. Standard quality assurance and control procedures were used for collecting, processing and reporting all pollutant measurements. Three measures of particulate air pollution were evaluated for their association with the blood inflammatory markers: all $\mathrm{PM}_{2.5}$, black carbon $(\mathrm{BC})$ and sulphate $\left(\mathrm{SO}_{4}{ }^{2-}\right)$. Ambient $\mathrm{PM}_{2.5}$ was measured with a tapered element oscillating microbalance (Model 1400A, Thermo Electron, East Greenbush, New York, USA), BC with an aethalometer (Magee Scientific, Berkeley, California, USA) and $\mathrm{SO}_{4}{ }^{2-}$ with a Harvard-EPA annular denuder system sampler. We used a season-specific correction factor, based on the data from a collocated gravimetric sampler, to compensate for loss of semi-volatile mass using the tapered element oscillating microbalance sampler. Particulate $\mathrm{SO}_{4}{ }^{2-}$ was measured as an integrated 24-h sample (from 09:00 to 09:00 h), with $\mathrm{PM}_{2.5}$ and $\mathrm{BC}$ measured hourly. Missing hourly data for $\mathrm{PM}_{2.5}$ and $\mathrm{BC}$ were imputed using regression modelling, including a long-term time trend, day of week, hour of day, temperature, relative humidity, barometric pressure and nitrogen dioxide as predictors, and the directly measured and imputed values used to construct $24 \mathrm{~h}$ averages (morning to morning).

$\mathrm{BC}$ is a component of $\mathrm{PM}_{2.5}$ frequently used to indicate traffic emissions, especially those related to diesel fuel combustion. $\mathrm{SO}_{4}{ }^{2-}$ particles are another component of $\mathrm{PM}_{2.5}$ originating primarily from coal-burning power plants, often transported regionally over long distances (eg, hundreds of kilometers). ${ }^{39}$ $\mathrm{PM}_{2.5}$ represents all combustion particles. $\mathrm{PM}_{2.5}$ concentrations were available for the entire study period, with $\mathrm{SO}_{4}{ }^{2-}$ concentrations available after October 1999 and BC concentrations after February 1999. Daily mean temperature, relative humidity and barometric pressure measurements were measured at the National Weather Service Station at Logan Airport (East Boston) located approximately $12 \mathrm{~km}$ from the diabetes clinic (Earth-Info, Boulder, Colorado, USA).

\section{Statistical analysis}

Clinical and environmental data were merged by date to evaluate associations with each particulate pollutant measure (in one-pollutant models) on the day of the patient's examination, controlling for patient characteristics and weather. In addition to the same-day pollution exposure, five other exposure periods were examined: the lagged moving averages of days 0 to 1, 2, 3, 4 and 5. Exposures up to 6 days before the examination day were chosen on the basis of research showing that multi-day average exposures predicted cardiovascular outcomes better.

The ICAM- 1 and VCAM- 1 variables were log transformed to achieve normal distribution. The vWF levels were expressed in percentages ( $100 \%$ being the normal mean value) and were normally distributed. Fewer vWF measurements were available than the ICAM-1 and VCAM-1, because these data were pooled from four distinct clinical trials, not all of which evaluated vWF. We also explored whether those participants not known to be taking lipid-lowering drugs, statins $(n=73)$ and those who had smoked in the past $(\mathrm{n}=39)$ had different associations between the inflammatory markers and air pollution, by excluding those known to be taking statins from one analysis and then stratifying by smoking status. The small number of patients taking statins $(n=19)$ precluded a robust analysis in this subgroup.

We used linear regression, controlling for patient characteristics selected a priori as likely predictors of ICAM-1, VCAM-1 and vWF concentrations, including age, sex, BMI, past smoking and race. Complete information was available for cholesterol 
Table 1 Demographic and clinical characteristics of study participants (all with type 2 diabetes)

\begin{tabular}{|c|c|}
\hline Categorical variables & $\begin{array}{l}n(\%) \\
n=92\end{array}$ \\
\hline \multicolumn{2}{|l|}{ Sex } \\
\hline Male & $55(60)$ \\
\hline Female & $37(40)$ \\
\hline \multicolumn{2}{|l|}{ Race } \\
\hline White & $84(91)$ \\
\hline Black & $6(7)$ \\
\hline Asian & $2(2)$ \\
\hline \multicolumn{2}{|l|}{ Smoking* } \\
\hline Ever & $39(42)$ \\
\hline Never & $53(58)$ \\
\hline Continuous variables & Mean (SD) $(n=36)$ \\
\hline Body mass index & $31.3(6.6)$ \\
\hline Age (years) & $56.6(10.6)$ \\
\hline $\mathrm{HbAlc}(\%)$ & $7.7(1.5)$ \\
\hline Total cholesterol (mg/dl) & $201.1(38.8)$ \\
\hline ICAM-1 (ng/ml) & $284.7(85.7)$ \\
\hline VCAM-1 (ng/ml) & $748.4(247.1)$ \\
\hline von Willebrand factor (\%)† & $120.9(48.3)$ \\
\hline \multicolumn{2}{|c|}{$\begin{array}{l}\text { HbAlc, glycosylated haemoglobin; ICAM-1, intercellular } \\
\text { adhesion molecule 1; VCAM-1, vascular cell adhesion molecule } 1 . \\
\text { *No patient had smoked within } 6 \text { weeks of study initiation. } \\
\text { tvon Willebrand factor was not available for all subjects. }\end{array}$} \\
\hline
\end{tabular}

levels, HbAlc and fasting blood glucose. Because fasting glucose levels were missing for five individuals, and were highly correlated with HbAlc (Pearson's correlation coefficient $0.82, \mathrm{p}<0.001$ ), we used HbAlc as a surrogate of glycaemic control. We included HbAlc and total cholesterol as these covariates may be related to inflammation.

Some observed ICAM-1 and VCAM-1 levels were relatively high, although all were within previously reported levels. To assess sensitivity to the influence of these extreme values, we re-conducted the analysis excluding values higher than the mean ( \pm 3 SD). Three VCAM-1 and four ICAM-1 observations fit this criterion.

To control for the potential impacts of weather, same-day apparent temperature (AT), an index of thermal comfort calculated from dew point and temperature, was included in the models as a linear term. AT is calculated as $\mathrm{AT}=-2.653+(0.994 \times \mathrm{Ta})+\left(0.0153 \times \mathrm{Td}^{2}\right)$, where $\mathrm{Ta}$ is air temperature and $\mathrm{Td}$ is dew point temperature. Indicator variables for the seasons were also included.

\section{RESULTS}

Complete information on the ICAM-1 and VCAM-1 outcomes and covariates used for the linear regressions was available for
91 of the participants with diabetes; 38 had data available for the vWF analysis (table 1). Most participants were white, aged $>50$ years and $60 \%$ were men. Among the 50 participants with BMI $>30 \mathrm{~kg} / \mathrm{m}^{2}$, about half were men and $63 \%$ were never smokers. Few participants were lean, with a mean BMI of $>25 \mathrm{~kg} / \mathrm{m}^{2}$ (the definition of overweight) among those with BMI $<30 \mathrm{~kg} / \mathrm{m}^{2}$.

Observed $24 \mathrm{~h} \mathrm{PM}_{2.5}$ levels in Boston were typically well below the US national standard of $65 \mu \mathrm{g} / \mathrm{m}^{3}$ ( $24 \mathrm{~h}$ average), with the highest level during the study being $33.7 \mu \mathrm{g} / \mathrm{m}^{3}$ (table 2). $\mathrm{PM}_{2.5}, \mathrm{BC}$ and meteorological measurements were available for every day the patients visited the clinic. In contrast, $\mathrm{SO}_{4}{ }^{2-}$ measurements were available for only 59 days. Positive and significant Spearman's correlations ( $\mathrm{r}$ ) were observed between $\mathrm{PM}_{2.5}$ and $\mathrm{SO}_{4}{ }^{2-}(\mathrm{r}=0.50, \mathrm{p}<0.001)$, and between $\mathrm{PM}_{2.5}$ and $\mathrm{BC}(\mathrm{r}=0.63, \mathrm{p}<0.001)$. There was little correlation between $\mathrm{BC}$ and $\mathrm{SO}_{4}{ }^{2-}(\mathrm{r}=0.07, \mathrm{p}=0.21)$, and small and non-significant correlations between the three particle pollutants and AT ( $\mathrm{r}=-0.17$ to 0.13 , respectively).

Table 3 shows results for the complete sample of participants with diabetes as well as for those who were not taking statins. Although CIs around the point estimates were wide, probably owing to sample size limitations, the point estimates for almost all lag times and inflammatory markers were positive, suggesting a trend. The exception was relationships between $\mathrm{SO}_{4}{ }^{2-}$ and VCAM-1 for which some negative point estimates were observed, but none were significant. The most consistent effects were seen for BC, with increases in inflammatory marker levels ranging from $4 \%$ to $28 \%$ according to the pollutant lag time. Most lags were significant for VCAM-1, with some significant associations with ICAM-1 and vWF. The effects tended to increase with longer lag times for the exposures. $\mathrm{PM}_{2.5}$ was significantly associated with increases in VCAM- 1 for the 5 and 6-day average exposures. When examining just those not taking statins, the point estimates of association between $\mathrm{PM}_{2.5}$ and both VCAM-1 and ICAM-1 were consistently higher than in the full population, with a few more associations attaining significance.

Among participants who reported having smoked in the past (but not within 6 months of study enrolment), associations between $\mathrm{PM}_{25}$ and $\mathrm{BC}$, and VCAM-1 were positive and significant for all but one of the exposure lags evaluated, ranging from $12 \%$ to almost $32 \%$ increases in this marker per interquartile range in the pollutant (table 4). All point estimates of association with these particles and vWF were positive, and three were significant (table 4). By contrast, among those who reported never smoking in the past, only one association, that between BC and VCAM-1, was positive and significant.

After removing the three extreme values of ICAM-1 and four for VCAM-1, some associations (particularly with BC and

Table 2 Descriptive statistics for environmental variables, Boston, Massachusetts, USA, between 1998 and 2002

\begin{tabular}{llccc}
\hline $\begin{array}{l}\text { Parameter (units; all } \\
\text { are 24 h means) }\end{array}$ & $\begin{array}{l}\text { Number of } \\
\text { observations }\end{array}$ & $\begin{array}{l}\text { Arithmetic } \\
\text { mean (SD) }\end{array}$ & Range & $\begin{array}{l}\text { Interquartile } \\
\text { range }\end{array}$ \\
\hline $\mathrm{AT}\left({ }^{\circ} \mathrm{C}\right)$ & 92 & $7.1(10.0)$ & $(-7.9,33.1)$ & 16.5 \\
$\mathrm{PM}{ }_{2.5}{ }^{*}\left(\mu \mathrm{g} / \mathrm{m}^{3}\right)$ & 92 & $11.4(5.9)$ & $(0.07,33.7)$ & 7.6 \\
$\mathrm{BC}+\left(\mu \mathrm{g} / \mathrm{m}^{3}\right)$ & 92 & $1.1(0.8)$ & $(0.2,5.8)$ & 0.6 \\
$\mathrm{SO}_{4}{ }^{2-} \neq\left(\mu \mathrm{g} / \mathrm{m}^{3}\right)$ & 59 & $3.0(2.0)$ & $(0.5,9.6)$ & 2.2 \\
\hline
\end{tabular}

AT, apparent temperature; $\mathrm{BC}$, black carbon; $\mathrm{PM}_{2.5}$, particles $<2.5 \mu \mathrm{m}$ in aerodynamic diameter, known as fine particles; $\mathrm{SO}_{4}{ }^{2-}$, sulphate.

*Particulate matter $<2.5 \mu \mathrm{m}$ in aerodynamic diameter measured by the Upright \& Patashnik Tapered Element Oscillating Microbalance sampler.

tBC measured by aethalometer (Magee Scientific).

$\ddagger \mathrm{SO}_{4}{ }^{2-}$ measured by the Harvard Annular Denuder System or by ion chromatography 
Table 3 Associations between particulate air pollutants and inflammatory markers, controlling for age, race, sex, past smoking, body mass index, cholesterol, glycosylated haemoglobin, season and apparent temperature, among subjects diagnosed with type 2 diabetes and those not taking statins

\begin{tabular}{|c|c|c|c|c|c|c|c|}
\hline \multirow[b]{2}{*}{ Pollutant } & \multirow[b]{2}{*}{ Exposure period } & \multicolumn{2}{|c|}{ ICAM-1 (ng/ml), \% change per IQR* } & \multicolumn{2}{|c|}{ VCAM-1 (ng/ml), \% change per IQR } & \multicolumn{2}{|c|}{ vWF (proportion), \% change per IQR } \\
\hline & & $n(\%)$ & $95 \% \mathrm{Cl}$ & $n(\%)$ & $95 \% \mathrm{Cl}$ & $n(\%)$ & $95 \% \mathrm{Cl}$ \\
\hline \multicolumn{8}{|c|}{ For all subjects } \\
\hline $\mathrm{PM}_{2.5}$ & $\begin{array}{l}\text { Lag } 0 \\
2 \text { dma } \\
3 \text { dma } \\
4 \text { dma } \\
5 \text { dma } \\
6 \text { dma }\end{array}$ & $\begin{array}{l}92(2.87) \\
92(2.25) \\
92(1.48) \\
92(1.80) \\
92(1.51) \\
92(2.12)\end{array}$ & $\begin{array}{l}-4.63 \text { to } 10.95 \\
-5.15 \text { to } 10.22 \\
-5.63 \text { to } 9.11 \\
-4.98 \text { to } 9.07 \\
-5.30 \text { to } 8.80 \\
-4.23 \text { to } 8.89\end{array}$ & $\begin{array}{l}92(6.88) \\
92(8.18) \\
92(6.92) \\
92(6.46) \\
92(8.57) \\
92(11.76)\end{array}$ & $\begin{array}{r}-2.88 \text { to } 17.62 \\
-1.43 \text { to } 18.72 \\
-1.66 \text { to } 16.25 \\
-1.16 \text { to } 14.66 \\
0.05 \text { to } 17.80 \\
3.48 \text { to } 20.70\end{array}$ & $\begin{array}{l}38(15.16) \\
38(12.57) \\
38(25.14) \\
38(23.42) \\
38(17.92) \\
38(20.48)\end{array}$ & $\begin{array}{r}-9.79 \text { to } 47.01 \\
-9.19 \text { to } 39.55 \\
-9.87 \text { to } 73.74 \\
-9.47 \text { to } 68.25 \\
-10.22 \text { to } 54.87 \\
-8.82 \text { to } 59.22\end{array}$ \\
\hline BC & $\begin{array}{l}\text { Lag } 0 \\
2 \text { dma } \\
3 \mathrm{dma} \\
4 \mathrm{dma} \\
5 \mathrm{dma} \\
6 \mathrm{dma}\end{array}$ & $\begin{array}{l}92(5.84) \\
92(5.08) \\
92(4.44) \\
92(5.02) \\
92(5.89) \\
92(6.73)\end{array}$ & $\begin{array}{l}0.87 \text { to } 11.05 \\
-2.34 \text { to } 13.07 \\
-2.70 \text { to } 12.11 \\
-1.78 \text { to } 12.29 \\
-2.14 \text { to } 14.58 \\
-1.54 \text { to } 15.70\end{array}$ & $\begin{array}{l}92(9.26) \\
92(10.18) \\
92(15.45) \\
92(17.97) \\
92(23.83) \\
92(27.51)\end{array}$ & $\begin{array}{r}2.98 \text { to } 15.91 \\
1.93 \text { to } 19.10 \\
2.70 \text { to } 29.78 \\
3.63 \text { to } 34.30 \\
8.41 \text { to } 41.44 \\
11.96 \text { to } 45.21\end{array}$ & $\begin{array}{l}38(7.96) \\
38(14.87) \\
38(15.34) \\
38(15.47) \\
38(19.50) \\
38(20.53)\end{array}$ & $\begin{array}{l}-4.34 \text { to } 21.84 \\
-2.85 \text { to } 35.82 \\
-3.22 \text { to } 37.45 \\
-7.60 \text { to } 44.31 \\
-8.89 \text { to } 56.74 \\
-9.80 \text { to } 61.05\end{array}$ \\
\hline \multirow[t]{2}{*}{ Sulphate } & $\operatorname{Lag} 0$ & $59(5.30)$ & -2.60 to 13.83 & $59(-0.04)$ & -3.75 to 3.80 & \multirow{2}{*}{\multicolumn{2}{|c|}{$\begin{array}{l}\text { Sulphate measurements not available on } \\
\text { days when blood was taken and assayed } \\
\text { for vWF }\end{array}$}} \\
\hline & $\begin{array}{l}2 \mathrm{dma} \\
3 \mathrm{dma} \\
4 \mathrm{dma} \\
5 \mathrm{dma} \\
6 \mathrm{dma}\end{array}$ & $\begin{array}{l}58(4.02) \\
61(4.03) \\
61(-0.79) \\
61(1.06) \\
61(3.15)\end{array}$ & $\begin{array}{l}-3.26 \text { to } 11.85 \\
-5.34 \text { to } 14.34 \\
-7.30 \text { to } 6.18 \\
-7.10 \text { to } 9.93 \\
-5.66 \text { to } 12.78\end{array}$ & $\begin{array}{l}58(0.94) \\
61(-0.87) \\
61(0.13) \\
61(-0.47) \\
61(-0.46)\end{array}$ & $\begin{array}{l}-4.79 \text { to } 7.01 \\
-3.50 \text { to } 1.82 \\
-2.02 \text { to } 2.34 \\
-2.67 \text { to } 1.78 \\
-1.99 \text { to } 1.09\end{array}$ & & \\
\hline \multicolumn{8}{|c|}{ For subjects not known to be taking statins } \\
\hline $\mathrm{PM}_{2.5}$ & $\begin{array}{l}\text { Lag } 0 \\
2 \text { dma } \\
3 \mathrm{dma} \\
4 \mathrm{dma} \\
5 \mathrm{dma} \\
6 \mathrm{dma}\end{array}$ & $\begin{array}{l}73(5.47) \\
73(5.70) \\
73(4.57) \\
73(4.57) \\
73(3.80) \\
73(3.79)\end{array}$ & $\begin{array}{l}-3.74 \text { to } 15.57 \\
-3.70 \text { to } 16.01 \\
-4.31 \text { to } 14.27 \\
-4.27 \text { to } 14.23 \\
-4.84 \text { to } 13.22 \\
-4.49 \text { to } 12.80\end{array}$ & $\begin{array}{l}73(10.26) \\
73(15.02) \\
73(14.59) \\
73(15.15) \\
73(16.16) \\
73(17.66)\end{array}$ & $\begin{array}{r}-0.64 \text { to } 22.35 \\
3.76 \text { to } 27.49 \\
3.94 \text { to } 26.34 \\
4.54 \text { to } 26.84 \\
5.77 \text { to } 27.58 \\
7.77 \text { to } 28.45\end{array}$ & $\begin{array}{l}32(7.40) \\
32(7.10) \\
32(10.78) \\
32(11.61) \\
32(9.15) \\
32(7.91)\end{array}$ & $\begin{array}{l}-19.82 \text { to } 43.88 \\
-19.09 \text { to } 41.76 \\
-17.92 \text { to } 49.52 \\
-16.64 \text { to } 49.42 \\
-20.32 \text { to } 49.53 \\
-20.70 \text { to } 46.85\end{array}$ \\
\hline BC & $\begin{array}{l}\text { Lag } 0 \\
2 \text { dma } \\
3 \mathrm{dma} \\
4 \mathrm{dma} \\
5 \mathrm{dma} \\
6 \mathrm{dma}\end{array}$ & $\begin{array}{l}73(6.04) \\
73(6.54) \\
73(5.86) \\
73(6.11) \\
73(6.89) \\
73(7.86)\end{array}$ & $\begin{array}{r}0.87 \text { to } 11.48 \\
-1.64 \text { to } 15.39 \\
-1.90 \text { to } 14.22 \\
-1.18 \text { to } 13.94 \\
-1.42 \text { to } 15.89 \\
-1.35 \text { to } 17.94\end{array}$ & $\begin{array}{l}73(9.19) \\
73(14.64) \\
73(14.39) \\
73(14.19) \\
73(19.11) \\
73(22.60)\end{array}$ & $\begin{array}{r}3.23 \text { to } 15.49 \\
5.02 \text { to } 25.14 \\
5.30 \text { to } 24.28 \\
5.71 \text { to } 23.36 \\
9.44 \text { to } 29.65 \\
11.79 \text { to } 34.45\end{array}$ & $\begin{array}{l}32(3.23) \\
32(9.82) \\
32(17.79) \\
32(13.14) \\
32(16.14) \\
32(13.25)\end{array}$ & $\begin{array}{r}-8.91 \text { to } 17.00 \\
-8.39 \text { to } 31.66 \\
-16.03 \text { to } 65.21 \\
-18.71 \text { to } 57.47 \\
-20.43 \text { to } 69.52 \\
-22.09 \text { to } 64.62\end{array}$ \\
\hline \multirow[t]{2}{*}{ Sulphate } & $\operatorname{Lag} 0$ & $44(10.14)$ & 0.44 to 20.77 & $44(-1.34)$ & -11.23 to 9.66 & \multirow{2}{*}{\multicolumn{2}{|c|}{$\begin{array}{l}\text { Sulphate measurements not available on } \\
\text { days when blood was taken and assayed } \\
\text { for vWF }\end{array}$}} \\
\hline & $\begin{array}{l}2 \mathrm{dma} \\
3 \mathrm{dma} \\
4 \mathrm{dma} \\
5 \mathrm{dma} \\
6 \mathrm{dma}\end{array}$ & $\begin{array}{l}46(9.39) \\
46(10.93) \\
44(-0.24) \\
46(4.03) \\
46(5.66)\end{array}$ & $\begin{array}{l}-1.28 \text { to } 21.20 \\
-2.23 \text { to } 25.85 \\
-9.66 \text { to } 10.16 \\
-8.66 \text { to } 18.47 \\
-7.52 \text { to } 20.72\end{array}$ & $\begin{array}{l}46(-0.19) \\
41(-2.84) \\
44(4.28) \\
46(-0.26) \\
46(-3.44)\end{array}$ & $\begin{array}{l}-11.13 \text { to } 12.09 \\
-13.90 \text { to } 9.64 \\
-6.18 \text { to } 15.90 \\
-13.44 \text { to } 14.93 \\
-16.51 \text { to } 11.67\end{array}$ & & \\
\hline
\end{tabular}

$B C$, black carbon; dma, day moving average; ICAM-1, intercellular adhesion molecule 1; IQR, interquartile range; $P M_{2.5}$, particles $<2.5 \mu \mathrm{m}$ in aerodynamic diameter, known as fine particles; VCAM-1, vascular cell adhesion molecule 1; vWF, von Willebrand factor.

${ }^{*} \mathrm{QR}$ of the pollutant for the exposure period under consideration.

ICAM-1) were found to have reduced and become nonsignificant. However, since the values were biologically plausible and the patterns of positive association remained consistent, the full sample was retained for the results reported here.

\section{DISCUSSION}

Among people with type 2 diabetes in Boston, airborne particles, especially BC concentrations, were significantly associated with increased levels of inflammatory markers that predict adverse cardiovascular effects. Although many of the estimates were imprecise owing to limited sample size, the overall trend of the point estimates was positive, consistent with recent epidemiological findings from other populations. When individuals taking statins were excluded from the analyses, we observed stronger associations with pollution among them, and among those with a history of smoking compared with those who had not smoked. We have previously shown that statins, which promote anti-inflammatory and antioxidant activity, can blunt the effects of air pollution on cardiac autonomic function, ${ }^{11}$ so the results seen here are consistent with that mechanism.

These results provide additional evidence suggesting that the enhanced susceptibility of people with diabetes to air pollution may be partly due to inflammatory mechanisms. Other research among a range of populations not comprised solely of people with diabetes evaluated similar inflammatory markers. Among 57 elderly German men with coronary artery disease, associations between various inflammatory markers and ambient air pollution levels, lagged up to 5 days prior to blood draw, were examined. ${ }^{32}$ Associations of $\mathrm{PM}_{10}$ with particles between $0.1 \mu \mathrm{m}$ and $1.0 \mu \mathrm{m}$ in aerodynamic diameter, as well as of elemental and organic carbon with corresponding plasma ICAM-1 concentrations above the 90th centile existed for lags 
Table 4 Associations between particulate air pollutants and inflammatory markers, controlling for age, race, sex, body mass index, cholesterol, glycosylated haemoglobin, season and apparent temperature, among subjects diagnosed with type 2 diabetes, by reported past smoking practices

\begin{tabular}{|c|c|c|c|c|c|c|c|}
\hline \multirow[b]{2}{*}{ Pollutant } & \multirow{2}{*}{$\begin{array}{l}\text { Exposure } \\
\text { period }\end{array}$} & \multicolumn{2}{|c|}{ ICAM-1 (ng/ml), \% change per IQR* } & \multicolumn{2}{|c|}{ VCAM-1 (ng/ml), \% change per IQR } & \multicolumn{2}{|c|}{ vWF (proportion), \% change per IQR } \\
\hline & & n (\%) & $95 \% \mathrm{Cl}$ & n $(\%)$ & $95 \% \mathrm{Cl}$ & n (\%) & $95 \% \mathrm{Cl}$ \\
\hline \multicolumn{8}{|c|}{ For subjects who report smoking in the past (but not within 6 months) } \\
\hline \multirow{6}{*}{$\mathrm{PM}_{2.5}$} & $\operatorname{Lag} 0$ & $39(0.9)$ & -9.56 to 12.66 & $39(13.2)$ & -1.30 to 29.72 & $24(19.23)$ & -24.29 to 87.77 \\
\hline & $2 \mathrm{dma}$ & $39(0.40)$ & -12.08 to 14.65 & $39(18.4)$ & 0.69 to 39.33 & $24(19.92)$ & -29.65 to 104.41 \\
\hline & $3 \mathrm{dma}$ & $39(1.34)$ & -9.23 to 13.14 & $39(15.7)$ & 1.19 to 32.30 & $24(29.54)$ & -17.24 to 102.76 \\
\hline & $4 \mathrm{dma}$ & 39 (2.29) & -6.84 to 12.30 & $39(13.1)$ & 0.88 to 26.78 & $24(41.98)$ & -6.95 to 116.63 \\
\hline & $5 \mathrm{dma}$ & 39 (1.09) & -8.30 to 11.44 & 39 (13.2) & 0.49 to 27.58 & $24(44.05)$ & -1.23 to 110.07 \\
\hline & $6 \mathrm{dma}$ & 39 (3.08) & -6.30 to 13.40 & 39 (16.2) & 3.76 to 30.10 & $24(50.39)$ & 9.35 to 106.82 \\
\hline \multirow[t]{6}{*}{$B C$} & Lag 0 & $39(5.09)$ & -2.37 to 13.11 & $39(12.4)$ & 2.77 to 22.92 & $24(7.63)$ & -17.01 to 39.58 \\
\hline & $2 \mathrm{dma}$ & 39 (3.97) & -10.24 to 20.42 & $39(28.5)$ & 8.38 to 52.24 & $24(37.64)$ & -7.18 to 104.10 \\
\hline & $3 \mathrm{dma}$ & $39(5.10)$ & -10.17 to 22.96 & $39(25.14)$ & 3.50 to 51.30 & $24(75.41)$ & 6.16 to 189.85 \\
\hline & $4 \mathrm{dma}$ & 39 (8.38) & -6.46 to 25.56 & $39(23.1)$ & 2.70 to 47.58 & $24(72.05)$ & -3.34 to 206.22 \\
\hline & $5 \mathrm{dma}$ & 39 (10.09) & -7.36 to 30.83 & $39(32.0)$ & 7.29 to 62.30 & $24(73.14)$ & 6.94 to 180.32 \\
\hline & $6 \mathrm{dma}$ & 39 (10.58) & -5.34 to 29.18 & 39 (31.8) & 9.74 to 58.26 & $24(71.23)$ & 14.00 to 157.19 \\
\hline \multirow[t]{6}{*}{ Sulphate } & $\operatorname{Lag} 0$ & $16(-4.00)$ & -24.79 to 22.52 & $16(0.07)$ & -23.40 to 30.73 & \multirow{6}{*}{\multicolumn{2}{|c|}{$\begin{array}{l}\text { Sulphate measurements not available on days } \\
\text { when blood was taken and assayed for vWF }\end{array}$}} \\
\hline & $2 \mathrm{dma}$ & $17(-4.82)$ & -18.01 to 10.48 & $17(-5.62)$ & -20.77 to 12.43 & & \\
\hline & $3 \mathrm{dma}$ & $17(-7.19)$ & -23.66 to 12.83 & $14(-26.92)$ & -33.31 to -19.91 & & \\
\hline & $4 \mathrm{dma}$ & $16(-9.8)$ & -27.96 to 12.97 & $16(-3.06)$ & -28.01 to 30.56 & & \\
\hline & $5 \mathrm{dma}$ & $17(-10.4)$ & -29.92 to 14.44 & $17(-6.42)$ & -30.75 to 26.47 & & \\
\hline & $6 \mathrm{dma}$ & $17(-6.8)$ & -25.72 to 17.03 & $17(-6.46)$ & -28.55 to 22.47 & & \\
\hline \multicolumn{8}{|c|}{ For subjects who did not report smoking in the past } \\
\hline \multirow[t]{6}{*}{$\mathrm{PM}_{2.5}$} & Lag 0 & $53(0.46)$ & -8.23 to 9.97 & $53(-3.12)$ & -12.41 to 7.17 & $14(-14.21)$ & -53.20 to 57.24 \\
\hline & $2 \mathrm{dma}$ & $53(1.37)$ & -7.96 to 11.65 & $53(-0.34)$ & -10.57 to 11.05 & $14(-20.66)$ & -63.14 to 70.77 \\
\hline & $3 \mathrm{dma}$ & $53(-0.96)$ & -10.01 to 9.00 & $53(-1.09)$ & -11.15 to 10.12 & $14(-28.89)$ & -68.43 to 60.19 \\
\hline & $4 \mathrm{dma}$ & $53(-1.34)$ & -10.35 to 8.58 & $53(-0.81)$ & -10.91 to 10.43 & $14(-23.51)$ & -55.11 to 30.34 \\
\hline & $5 \mathrm{dma}$ & $53(-0.87)$ & -10.17 to 9.40 & $53(2.07)$ & -8.59 to 13.96 & $14(-29.18)$ & -60.08 to 25.66 \\
\hline & $6 \mathrm{dma}$ & $53(-1.78)$ & -10.64 to 7.94 & $53(4.89)$ & -5.56 to 16.50 & $14(-30.68)$ & -55.95 to 9.08 \\
\hline \multirow[t]{6}{*}{$B C$} & $\operatorname{Lag} 0$ & $53(5.77)$ & -3.92 to 16.44 & $53(5.15)$ & -5.63 to 17.17 & $14(10.22)$ & -23.14 to 58.04 \\
\hline & $2 \mathrm{dma}$ & $53(2.39)$ & -7.65 to 13.52 & $53(2.09)$ & -9.07 to 14.61 & $14(17.07)$ & -18.86 to 68.91 \\
\hline & $3 \mathrm{dma}$ & $53(0.84)$ & -8.16 to 10.73 & $53(3.90)$ & -6.38 to 15.31 & $14(6.56)$ & -42.75 to 98.36 \\
\hline & $4 \mathrm{dma}$ & $53(1.67)$ & -6.71 to 10.80 & $53(4.92)$ & -4.63 to 15.43 & $14(-9.20)$ & -65.79 to 140.99 \\
\hline & $5 \mathrm{dma}$ & $53(1.55)$ & -6.46 to 10.24 & $53(7.89)$ & -1.31 to 17.95 & $14(-23.86)$ & -71.05 to 100.29 \\
\hline & $6 \mathrm{dma}$ & $53(2.20)$ & -6.47 to 11.68 & $53(10.97)$ & 0.98 to 21.96 & $14(-48.69)$ & -77.75 to 18.29 \\
\hline \multirow[t]{6}{*}{ Sulphate } & $\operatorname{Lag} 0$ & $42(6.67)$ & -4.34 to 18.94 & $42(-3.28)$ & -12.66 to 7.12 & \multirow{6}{*}{\multicolumn{2}{|c|}{$\begin{array}{l}\text { Sulphate measurements not available on days } \\
\text { when blood was taken and assayed for vWF }\end{array}$}} \\
\hline & $2 \mathrm{dma}$ & $44(5.65)$ & -4.67 to 17.10 & $44(-3.17)$ & -11.75 to 6.23 & & \\
\hline & $3 \mathrm{dma}$ & $44(10.21)$ & -5.83 to 28.99 & $40(-9.67)$ & -22.07 to 4.70 & & \\
\hline & $4 \mathrm{dma}$ & $43(0.80)$ & -9.94 to 12.83 & $43(-5.51)$ & -14.28 to 4.15 & & \\
\hline & $5 \mathrm{dma}$ & $44(2.80)$ & -10.85 to 18.54 & $44(-12.17)$ & -22.05 to -1.05 & & \\
\hline & $6 \mathrm{dma}$ & $44(5.15)$ & -7.78 to 19.89 & $44(-11.77)$ & -20.95 to -1.52 & & \\
\hline
\end{tabular}

$\mathrm{BC}$, black carbon; dma, day moving average; ICAM-1, intercellular adhesion molecule 1 ; IQR, interquartile range; $\mathrm{PM}_{2.5}$, particles $<2.5 \mu \mathrm{m}$ in aerodynamic diameter known as fine particles; VCAM-1, vascular cell adhesion molecule 1; vWF, von Willebrand factor.

${ }^{*} \mathrm{QQR}$ of the pollutant for the exposure period under consideration.

1 and $2 .{ }^{32}$ No significant associations with ICAM-1 were seen using linear regression. This observation is consistent with the hypothesis that individuals in the upper end of the distribution for certain subclinical parameters are the most sensitive. For vWf, statistically significant positive associations were seen for $\mathrm{PM}_{2.5}$ and for particles between $0.1 \mu \mathrm{m}$ and $1.0 \mu \mathrm{m}$ in aerodynamic diameter only for the 5 -day average exposure. ${ }^{32}$

In a population of 10208 middle-aged men and women in the US, an increase of $12.8 \mu \mathrm{g} / \mathrm{m}^{3}$ of $\mathrm{PM}_{10}$ (measured using ambient monitors) the day before the blood draw was associated with a $3.93 \%$ increase in vWF $(\mathrm{p}<0.05)$, controlling for age, sex, ethnicity, cardiovascular and respiratory disease history, weather, education, smoking, drinking and BMI. ${ }^{30}$ Levels of $\mathrm{PM}_{10}$ measured 2-3 days before the blood draw were not associated with any of the haemostatic and inflammatory markers evaluated in that study, and multiday averages were not examined.$^{30}$ In a study of healthy young male state troopers in North Carolina, vWF levels increased $11.8 \%(\mathrm{p}=0.018)$ with each $10 \mu \mathrm{g} / \mathrm{m}^{3}$ increase in $\mathrm{PM}_{2.5}$ measured inside patrol cars
10-14 h prior to the blood draw. ${ }^{31}$ All three studies, although carried out in diverse populations with differing exposure assessment, find results consistent with the pattern observed in ours. People with diabetes are likely to have higher levels of inflammation than other populations, such as healthy young males, but these differences are not likely to confound associations between inflammatory markers and air pollution, and the consistency of associations across all our studies suggests that this mechanism is one plausible explanation for the observed links between air pollution and adverse cardiovascular events. It is worth noting that many of our participants were in the obese range, and obesity was associated with a greater inflammatory effect of PM (results not shown). However, since obesity, hypertension, hyperlipidaemia and glucose control are all interconnected, it was not possible to discern which of these factors increased vulnerability to PM.

In addition to epidemiological research, controlled exposure studies offer evidence of an inflammatory mechanism that includes endothelial activation (as indicated by cellular adhesion 
molecules) for air pollution health effects. A controlled exposure study showed that after human volunteers inhaled $300 \mu \mathrm{g} / \mathrm{m}^{3}$ of diesel particles for $1 \mathrm{~h}$, increased levels of ICAM-1 and VCAM-l were expressed in the bronchial lining fluid and tissue. ${ }^{29}$ Another study exposed healthy and asthmatic subjects for $2 \mathrm{~h}$ to $100 \mu \mathrm{g} /$ $\mathrm{m}^{3}$ of diesel particles. Levels of VCAM-l on the vascular endothelium from a bronchial biopsy specimen increased twofold among healthy subjects $6 \mathrm{~h}$ after exposure, but no changes were observed among those with asthma, and ICAM-1 levels did not change in either group after exposure. ${ }^{28}$ In another study, healthy subjects and subjects with asthma were exposed to $200 \mu \mathrm{g} / \mathrm{m}^{3}$ concentrated ambient particles in the fine $(<2.5 \mu \mathrm{m}$ aerodynamic diameter) size range for $2 \mathrm{~h}$, and then to filtered air. Plasma concentrations of ICAM-1 were measured in venous blood samples taken just before exposure, then 4 and $22 \mathrm{~h}$ after exposure. Soluble ICAM-1 increased in both healthy subjects and subjects with asthma $4 \mathrm{~h}$ after exposure to the concentrated ambient particles, with even higher levels $22 \mathrm{~h}$ afterwards, but not among the same subjects exposed to filtered air. ${ }^{27}$ In another chamber study, 2-h exposures to $150 \mu \mathrm{g} / \mathrm{m}^{3}$ of diesel particles were found to enhance levels of VCAM-1 in the bronchial mucosa among healthy subjects, but not among those with mild asthma, but ICAM-1 levels were not increased after diesel exposure in either group. ${ }^{33}$

We evaluated, in a free-living population, associations with particles whose chemical composition broadly links them with different pollutant sources. The associations between BC and VCAM-1 observed in our study are consistent with the findings on diesel chamber exposure. Positive and significant associations were seen, especially among individuals not taking statins and those who had a history of smoking, which may reflect cardiovascular damage and/or a residual inflammatory burden from this practice. These results provide some indication that mobile source emissions (as indicated by $\mathrm{BC}$ ) may have a preferential mechanism of action in promoting VCAM-1 activation. Corresponding results were not seen between $\mathrm{SO}_{4}{ }^{2-}$ and the inflammatory markers, which, particularly in the Boston area, reflect regional contributions from coalburning power plants. For associations between $\mathrm{SO}_{4}{ }^{2-}$ and the inflammatory markers for this study, only two positive and significant associations were observed, although sample size was smaller than for $\mathrm{BC}$ and $\mathrm{PM}_{2.5}$ owing to limited monitoring of $\mathrm{SO}_{4}{ }^{2-}$ during the study period.

The differences between the effect estimates for the various particle sources were not great, but tended towards larger effects with the longer exposure averaging times for both $\mathrm{PM}_{2.5}$ and $\mathrm{BC}$ and the adhesion molecules. Not all previous studies have examined such long lags for exposures-for example, the Liao study examined pollution levels 1, 2 and 3 days prior, ${ }^{30}$ and the Riediker study looked at just 1 day before the blood draws. ${ }^{31}$ Cumulative exposures over several days may be important for activation of inflammatory and vascular responses. Alternatively, averaging particle measurements over several days may reduce measurement error and hence yield stronger associations, even though the window of relevance for activating an inflammatory response may be much shorter. Longer-lag periods should be considered in future epidemiological study designs.

The differences between ICAM- 1 and VCAM- 1 are potentially relevant for interpreting results of the present study. Increased plasma ICAM-1 levels may indicate a general inflammatory state and upregulation in non-endothelial cells, whereas the VCAM-1 may have a more restricted distribution in the vascular system, thus explaining less consistent associations between VCAM- 1 and certain clinical outcomes. ${ }^{18}$ Indeed, very little is known about the determinants and regulation of plasma concentrations of these molecules. Caution has therefore been urged in interpretation of disparate studies on their utility for predicting clinical disease, especially since the published studies have not controlled for a consistent set of clinical covariates. ${ }^{13}$ We were interested in the associations between these two markers of inflammation and particulate pollutants; the varying patterns of association we observed may be partly because of their differential distributions in the vasculature. In our study, we evaluated levels of these molecules in plasma, not using immunohistochemistry, further limiting the ability to identify the source (endothelial vs systemic) of these molecules, since they were not measured on cell surfaces.

The strengths and limitations of using ambient monitors to assign air pollution exposure in a cross-sectional study have been discussed. ${ }^{34}$ In brief, differences in the spatial homogeneity for each particle measure may affect the degree of measurement error involved in using a single outdoor monitor as a surrogate of personal exposure. However, a single, centrally located monitor has been used to estimate exposure to particles of the size fraction and composition we were evaluating in other similar studies, ${ }^{32}$ and comparisons of levels monitored at various sites around Boston suggest that one monitor can provide a reasonable estimate of personal exposure. ${ }^{39}$ Particle measurements with numerous local sources, such as mobile source emissions of $\mathrm{BC}$, are typically more spatially heterogeneous than regional pollutants such as $\mathrm{SO}_{4}{ }^{2-}$. Therefore, we would have expected associations to be most attenuated for BC due to measurement error. This was not the case, as most of the strongest observed associations involved $\mathrm{BC}$ and not $\mathrm{SO}_{4}{ }^{2-}$.

This cross-sectional study contributes to a growing body of literature that suggests that inflammation may be an

\section{Main messages}

- Hospital admissions and deaths linked to particulate air pollution exposure disproportionately affect people with diabetes, but the biological mechanisms are not fully known.

- Inflammatory blood markers were found increased, some significantly so, after periods of higher ambient particulate pollution, among individuals with diabetes, after controlling for other individual risk factors associated with inflammation.

- These results are consistent with previous reports suggesting that inflammation may be an important biological mechanism explaining susceptibility to cardiovascular effects associated with air pollution exposure among people with diabetes.

\section{Policy implications}

- Air quality standards are intended to protect the most vulnerable populations, and understanding the mechanisms of how diabetes may contribute to vulnerability is an important part of the evidence base for setting and enforcing protective standards.

- Individual and clinical risk factors are probably not the only contributors to the burden of ill health among people with diabetes; environmental quality may be an important intervention to improve quality of life in this population. 
explanatory factor for the greater risk for adverse cardiovascular consequences due to exposure to airborne particles in people with diabetes. Additional studies with larger sample size in differing locales with higher pollution levels, or different pollutant mixes, would be needed to confirm these findings. However, the present evidence is consistent with other studies showing greater air pollution sensitivity among individuals with diabetes. If the preponderance of evidence continues to confirm this potential susceptibility, environmental, in addition to lifestyle and medical, interventions may need to be considered to improve the quality of life among the growing population of people with diabetes.

\section{ACKNOWLEDGEMENTS}

This work was supported by the National Institute of Environmental Health Sciences, National Institutes of Health (Grant numbers 2 T32 ES07069-24 (NIEHS, NIH); NIEHS ES00002; 2P30-DK-36836 (NIH); RR 01032 (NIH); POI ES009825), the US Environmental Protection Agency (EPA R827353); Pfizer; American Diabetes Association; Parke Davis; Juvenile Diabetes Foundation International; William Randolph Hearst Foundation; Iacocca Foundation; and Robert Wood Johnson Foundation. Tania Kotlov, Sung Kyun Park, Caitlin Sparks and Elizabeth Tiani contributed to data collection and management.

\section{Authors' affiliations}

M S O'Neill, Departments of Epidemiology and Environmental Health Sciences, University of Michigan School of Public Health, Ann Arbor, Michigan, USA

A Veves, Beth Israel Deaconess Medical Center, Boston, Massachusetts, USA

J A Sarnat, Emory University School of Public Health, Atlanta, Georgia, USA

A Zanobetti, D R Gold, J Schwartz, Department of Environmental Health, Harvard School of Public Health, Boston, Massachusetts, USA P A Economides, Center for Endocrinology and Metabolism, Nicosia, Cyprus

E S Horton, Joslin Diabetes Center, Boston, Massachusetts, USA

Competing interests: None.

\section{REFERENCES}

1 Gent JF, Triche EW, Holford TR, et al. Association of low-level ozone and fine particles with respiratory symptoms in children with asthma. JAMA 2003:290:1859-67.

2 Brunekreef B, Holgate ST. Air pollution and health. Lancet 2002;360:1233-42.

3 Nemmar A, Hoet PH, Vanquickenborne B, et al. Passage of inhaled particles into the blood circulation in humans. Circulation 2002;105:411-14.

4 Brook RD, Franklin B, Cascio W, et al. Air pollution and cardiovascular disease: a statement for healthcare professionals from the Expert Panel on Population and Prevention Science of the American Heart Association. Circulation 2004; 109:2655-71

5 Seaton A, Soutar A, Crawford V, et al. Particulate air pollution and the blood. Thorax 1999:54:1027-32.

6 Gurgueira SA, Lawrence J, Coull B, et al. Rapid increases in the steady-state concentration of reactive oxygen species in the lungs and heart after particulate air pollution inhalation. Environ Health Perspect 2002;110:749-55.

7 Rhoden CR, Lawrence J, Godleski JJ, et al. N-acetylcysteine prevents lung inflammation after short-term inhalation exposure to concentrated ambien particles. Toxicol Sci 2004;79:296-303.

8 Goldberg MS, Burnett RT, Bailar JC 3rd, et al. The association between daily mortality and ambient air particle pollution in Montreal, Quebec. 2. Causespecific mortality. Environ Res 2001;86:26-36.

9 Zanobetti A, Schwartz J. Cardiovascular damage by airborne particles: are diabetics more susceptible? Epidemiology 2002;13:588-92.

10 Jerrett M, Burnett RT, Ma R, et al. Spatial analysis of air pollution and mortality in Los Angeles. Epidemiology 2005;16:727-36.

11 Schwartz J, Park SK, O'Neill MS, et al. Glutathione-S-transferase M1, obesity, statins, and autonomic effects of particles gene-by-drug environment interaction. Am J Respir Crit Care Med 2005;172:1529-33.

12 Dubowsky SD, Suh H, Schwartz J, et al. Diabetes, obesity, and hypertension may enhance associations between air pollution and markers of systemic inflammation. Environ Health Perspect 2006;1 14:992-8.
13 Ballantyne CM, Entman ML. Soluble adhesion molecules and the search for biomarkers for atherosclerosis. Circulation 2002;106:766-7.

14 Blann AD, Ridker PM, Lip GY. Inflammation, cell adhesion molecules, and stroke: tools in pathophysiology and epidemiology? Stroke 2002;33:2141-3.

15 Conway DS, Pearce LA, Chin BS, et al. Plasma von Willebrand factor and soluble $\mathrm{p}$-selectin as indices of endothelial damage and platelet activation in 1321 patients with nonvalvular atrial fibrillation: relationship to stroke risk factors. Circulation 2002;106:1962-7.

16 Whincup PH, Danesh J, Walker M, et al. von Willebrand factor and coronary heart disease: prospective study and meta-analysis. Eur Heart $J$ 2002;23:1764-70

17 Luc G, Arveiler D, Evans A, et al. Circulating soluble adhesion molecules ICAM-1 and VCAM-1 and incident coronary heart disease: the PRIME Study. Atherosclerosis 2003:170:169-76.

18 Pradhan AD, Rifai N, Ridker PM. Soluble intercellular adhesion molecule-1, soluble vascular adhesion molecule-1, and the development of symptomatic peripheral arterial disease in men. Circulation 2002;106:820-5.

19 Witte DR, Broekmans WM, Kardinaal AF, et al. Soluble intercellular adhesion molecule 1 and flow-mediated dilatation are related to the estimated risk of coronary heart disease independently from each other. Atherosclerosis 2003; 170: 147-53.

20 Blankenberg S, Rupprecht HJ, Bickel C, et al. Circulating cell adhesion molecules and death in patients with coronary artery disease. Circulation 2001;104:1336-42.

21 Haim M, Tanne D, Boyko V, et al. Soluble intercellular adhesion molecule-1 and long-term risk of acute coronary events in patients with chronic coronary heart disease. Data from the Bezafibrate Infarction Prevention (BIP) Study. J Am Coll Cardiol 2002;39:1133-8.

22 Malik I, Danesh J, Whincup P, et al. Soluble adhesion molecules and prediction of coronary heart disease: a prospective study and meta-analysis. Lancet 2001;358:971-6.

23 Folsom AR, Wu KK, Rosamond WD, et al. Prospective study of hemostatic factors and incidence of coronary heart disease: the Atherosclerosis Risk in Communities (ARIC) Study. Circulation 1997;96:1102-8

24 Conway DS, Buggins P, Hughes E, et al. Predictive value of indexes of inflammation and hypercoagulability on success of cardioversion of persisten atrial fibrillation. Am J Cardiol 2004:94:508-10.

25 Lim SC, Caballero AE, Smakowski P, et al. Soluble intercellular adhesion molecule, vascular cell adhesion molecule, and impaired microvascular reactivity are early markers of vasculopathy in type 2 diabetic individuals without microalbuminuria. Diab Care 1999:22:1865-70.

26 Meigs JB, Hu FB, Rifai N, et al. Biomarkers of endothelial dysfunction and risk of type 2 diabetes mellitus. JAMA 2004;291:1978-86.

27 Holgate ST, Devlin RB, Wilson SJ, et al. Health effects of acute exposure to air pollution. Part II: healthy subjects exposed to concentrated ambient particles. Res Rep Health Eff Inst, 2003;1 12:31-50.

28 Holgate ST, Sandstrom T, Frew AJ, et al. Health effects of acute exposure to air pollution. Part I: healthy and asthmatic subjects exposed to diesel exhaust. Res Rep Health Eff Inst, 2003;112:1-30.

29 Salvi S, Blomberg A, Rudell B, et al. Acute inflammatory responses in the airways and peripheral blood after short-term exposure to diesel exhaust in healthy human volunteers. Am J Resp Crit Care Med 1999;159:702-9.

30 Liao D, Heiss G, Chinchilli VM, et al. Association of criteria pollutants with plasma hemostatic/inflammatory markers: a population-based study. J Expos Anal Environ Epidemiol 2005;15:319-28.

31 Riediker M, Cascio WE, Griggs TR, et al. Particulate matter exposure in cars is associated with cardiovascular effects in healthy young men. Am J Resp Crit Care Med 2004; 169:934-40

32 Ruckerl R, Ibald-Mulli A, Koenig W, et al. Air pollution and markers of inflammation and coagulation in patients with coronary heart disease. Am J Resp Crit Care Med 2005; 172:1529-33.

33 Stenfors N, Nordenhall C, Salvi SS, et al. Different airway inflammatory responses in asthmatic and healthy humans exposed to diesel. Eur Resp J 2004;23:82-6

34 O'Neill MS, Veves A, Zanobetti A, et al. Diabetes enhances vulnerability to particulate air pollution-associated impairment in vascular reactivity and endothelial function. Circulation 2005;111:2913-20.

35 Caballero AE, Saouaf R, Lim SC, et al. The effects of troglitazone, an insulinsensitizing agent, on the endothelial function in early and late type 2 diabetes: a placebo-controlled randomized clinical trial. Metabolism 2003;52:173-80.

36 Economides PA, Caselli A, Khaodhiar L, et al. Effects of the angiotensin converting enzyme inhibitor Quinapril on endothelial function and kidney oxygenation in type 2 diabetes mellitus and in subjects at risk for diabetes. Diabetes 2004;53:A123.

37 Economides PA, Caselli A, Tiani E, et al. The effects of atorvastatin on endothelial function in diabetic patients and subjects at risk for type 2 diabetes. J Clin Endocrinol Metab 2004:89:740-7.

38 Economides PA, Khaodhiar L, Caselli A, et al. The effect of vitamin E on endothelial function of micro- and macrocirculation and left ventricular function in type 1 and type 2 diabetic patients. Diabetes 2005;54:204-11.

39 Thurston GD, Spengler JD. A quantitative assessment of source contributions to inhalable particulate matter pollution in metropolitan Boston. Atmos Environ 1985;19:9-25. 